\title{
Revitalisasi dan Perubahan Fungsi Sastra Lisan dalam Komunitas Srandul Suketeki
}

\author{
Rahma Ari Widihastuti ${ }^{1}$ \\ ${ }^{1}$ Jurusan Bahasa dan Sastra Jawa, Fakultas Bahasa dan Seni, Universitas Negeri Semarang, \\ Sekaran, Gunung Pati, Semarang, Jawa Tengah 50229 \\ Penulis untuk Korespondensi/E-mail: rahmajawa@mail.unnes.ac.id
}

\begin{abstract}
The development of the era resulted in the erosion and displacement of oral literature in social life. Modern arts have succeeded in replacing traditional arts, including srandul oral literature. Development and improvisation are some of the ways are taken to save oral literature. This study aims to determine the revitalization in the effort to preserve the srandul, especially the Srandul Suketeki community, and the changes in function in the oral literature of srandul. The method used is a descriptive qualitative method and ethnographic method and uses oral literature theory proposed by Ruth Finnegan. The results showed that the revitalization in the srandul arts of the Suketeki Community was carried out in three aspects: 1) composition (creation), transmission (inheritance), and performance (show). In Finnegan's opinion, these three things are maintained to keep the srandul of the Suketeki Community into oral literature. The change in function that arises due to revitalization is the initial function of Srandul's oral literature which was originally a propagator of Islamic preaching, became entertainment, and is now a means of criticism, especially on government policies.
\end{abstract}

Abstrak - Perkembangan jaman mengakibatkan semakin tergerus dan tergusurnya sastra lisan dalam kehidupan bermasyarakat. Kesenian-kesenian modern berhasil menggantikan posisi kesenian tradisional termasuk sastra lisan srandul. Perkembangan dan improvisasi adalah salah satu cara yang ditempuh untuk menyelamatkan sastra lisan. Penelitian ini bertujuan untuk mengetahui revitalisasi dalam upaya pelestarian srandul khususnya komunitas Srandul Suketeki dan perubahan fungsi dalam sastra lisan srandul. Metode yang digunakan adalah metode deskriptif kualitatif dan metode etnografi serta menggunakan teori sastra lisan yang dikemukakan Ruth Finnegan. Hasil penelitian menunjukkan bahwa revitalisasi dalam kesenian srandul Komunitas Suketeki dilakukan dalam tiga segi:1) composition (penciptaan), transmission (pewarisan), dan performance (pertunjukkan). Sesuai pendapat Finnegan ketiga hal tersebut dijaga agar tetap menjadi ciri agar srandul Komunitas Suketeki tetap menjadi sastra lisan. Perubahan fungsi yang muncul akibat adanya revitalisasi adalah fungsi awal sastra lisan srandul yang pada mulanya sebagai penyebar dakwah islam, menjadi hiburan, dan saat ini menjadi sarana kritik terutama pada kebijakan pemerintah.

Keyword - Function change,Oral literature, Revitalization, Srandul suketeki 


\section{PENDAHULUAN}

Sastra lisan dikenal sebagi peninggalan masyarakat jaman dahulu yang belum mengenal tulisan. Oleh sebab itu, sifat sastra lisan cenderung statis dan tidak mengalami perubahan yang berarti. Di jaman dahulu, sastra lisan lebih berfungsi sebagai hiburan. Hal ini dikarenakan minimnya kegiatan yang dilakukan masyarakat sehingga kesenian kolektif menjadi salah satu wadah ekspresi dan diwariskan secara turun temurun dengan cara lisan. Salah satu kesenian kolektif yang masih eksis hingga saat ini adalah srandul. Kesenian srandul tidak di ketahui secara pasti pendirinya, namun dipercaya bahwa kesenian srandul sudah ada sejak zaman wali. Masyarakat beranggapan bahwa kesenian srandul merupakan kesenian turun-temurun dari para pendahulunya [1]. Jabrohim mengungkapkan, kata srandul berasal dari bahasa Jawa pating srendul, bermakna saling campur aduk atau tidak tertata rapi [2]. Akan tetapi, Anggraini memiliki pendapat yang berbeda, menurutnya, srandul berasal dari bahasa Jawa srana yang berarti alat atau sarana serta andil/andhul yang berarti mengikuti, sehingga srandul dapat dimaknai sebagai sarana atau alat yang menarik masyarakat agar mengikuti [3].

Kesenian tradisi srandul menggabungkan tiga komponen utama yaitu tembung, tembang, dan joged sehingga mampu menarik perhatian masyarakat dengan penyisipan ajaran agama Islam. Cerita dan tokoh srandul yang berada di kota Yogyakarta memiliki perbedaan. Senada dengan penelitian yang dilakukan oleh Supriyanto bahwa kesenian srandul tidak hanya terdapat di Gunungkidul saja, tetapi juga terdapat di daerah lain, yang masing-masing memiliki ciri khas sendiri sesuai dengan daerah tempat kesenian srandul hidup [4]. Jika inspirasi utama cerita srandul di Yogyakarta adalah dari Babad Demak, maka di daerah lain menyesuaikan dengan legenda yang beredar di sekitar sekaligus menyesuaikan dengan keadaan masyarakat yang ada di daerah tersebut. Hal ini kemudian yang mempengaruhi ciri khas cerita srandul dari masing-masing daerah yang telah dilalui oleh para wali.

Tidak ada teks tertulis naskah drama srandul. Para lakon dan pegiat mendasarkan pada hafalan dan ingatan, selanjutnya melakukan improvisasi ketika berada di atas panggung. Hal ini merupakan ciri khas dari sastra lisan. Ada beberapa komunitas srandul yang masih eksis di daerah Prambanan, Yogyakarta. Yogyakarta memang dikenal sebagai daerah dengan perhatian pada kebudayaan yang tinggi. Masyarakat begitu sadar akan pentingnya budaya dan selalu terlibat aktif untuk melestarikan bahkan mengembangkannya. Ironisnya, pernah terjadi pula kevakuman generasi yang menyebabkan sebuah kesenian termasuk sastra lisan sehingga hampir mengalami kepunahan.

Di Prambanan, terdapat salah satu komunitas srandul yang mencoba bangkit dengan konsep anyar, mengembalikan eksistensi srandul yang cukup lama vakum. Tepatnya di dukuh Karangmojo dan dipandegani oleh Pak Kusumo, tahun 2014 lahirlah Komunitas Srandul Suketeki. Suketeki diambil dengan filosofi yang dimiliki rumput suketeki. Rumput jenis suketeki dikenal dengan sifat yang kuat dalam kondisi apapun, hujan, panas, diinjak berkali-kali, suketeki akan tumbuh dan bangkit lagi. Berdasar sifat yang dimiliki suketeki ini, komunitas Srandul Suketeki memiliki cita-cita untuk terus melestarikan seni tradisi srandul di jaman modern. Pada mulanya, pertunjukkan difungsikan sebagai hiburan masyarakat sekitar, semakin lama lingkup pertunjukkan diperluas dan berani tampil di panggung-panggung kota.

Keberanian mengubah beberapa hal yang telah turun temurun dari kesenian srandul membuatnya khas. Pak Kusumo mengaku sebelum pentas beliau membuat naskah terlebih dahulu. Padahal dalam teorinya, sastra lisan dikenal sebagai sastra yang segala hal didominasi dengan kegiatan lisan, termasuk dengan penciptaan bahkan pewarisannya. Namun hal ini tidak kemudian membuat kesenian srandul kehilangan ciri sebagai salah satu sastra lisan. Seperti yang disebutkan [5] bahwa sastra lisan tidak sepenuhnya berkembang secara lisan (kelisanan). Selanjutnya, Suwardi menjelaskan bahwa dalam kondisi yang semakin berkembang, termasuk campur tangan elektronik, tentu akan mengubah sastra lisan dan membuatnya rumit. Namun hal tersebut justru membuat menarik untuk meneliti sastra lisan. Seperti halnya menurut Hutomo, meskipun semakin jauh dari sumbernya foklor yang disebarkan secara lisan banyak mengalami perubahan, tetapi intinya tetap sama [5].

Sastra lisan menyimpan banyak fungsi bagi masyarakat sekitarnya maupun masyarakat secara luas karena di dalam sastra lisan terkandung banyak sekali hal yang dapat diambil. Sebuah pernyataan yang menyatakan sastra lisan turut menjadi salah satu sumber karakter bangsa dapat dibenarkan. Kandungan pesan dalam sastra lisan di masingmasing daerah mayoritas mengajak masyarakatnya 
untuk berperilaku baik, tidak melupakan asal usul, dan menjunjung tinggi kerukunan.

Penelitian mengenai srandul telah banyak dilakukan, tetapi yang berfokus pada sastra lisan atau teksnya hanya beberapa saja. Penelitian sebelumnya mengenai Komunitas Srandul Suketeki telah dilakukan oleh Rahma Ari Widihastuti dalam tesisnya [6]. Penelitian ini merupakan sebagian kecil dari penelitian tersebut yang berfokus hanya pada srandul Komunitas Suketeki. Selain itu, penelitian oleh Sunahrowi (2015), Sulistianto (2016), Supriyanto (2020), Fandy Aprianto Rohman (2020). Perbedaan penelitian ini dengan penelitianpenelitian sebelumnya adalah fokus utama atau objek penelitian berupa teks atau sastra lisan kesenian srandul.

Rahma Ari Widihastuti dalam tesisnya yang berjudul "Revitalisasi, Perubahan Fungsi, dan Perubahan Konteks Sosial Masyarakat dalam Sastra Lisan Srandul di Dukuh Plempoh dan Dukuh Karangmojo, Yogyakarta" memaparkan usaha para pegiat srandul sebagai upaya pelestarian dan menjaga keeksisan srandul terutama di daerah Bokoharjo dan Prambanan. Dalam tesis ini juga disampaikan bahwa Komunitas Srandul Suketeki merupakan salah satu komunitas yang berani membangkitkan kembali eksistensi srandul dengan konsep yang berbeda dan lain dengan komunitas srandul lainnya [6].

Sunahrowi dalam artikelnya berjudul "Pembentukan Karakter Anak melalui Kesenian Tradisional Srandul: Kajian Semiotika Roland Barthes" memberikan salah satu alternatif bagi penanaman karakter bagi anak-anak sekaligus penyelamatan kesenian tradisi srandul dari kepunahan. Dalam artikelnya, Sunahrowi menyatakan bahwa srandul memiliki kandungan nilai-nilai karakter yang baik dan harus disebarkan pada generasi penerus [7].

Sulistianto dalam artikelnya berjudul "Kesenian Srandul di Dusun Karangmojo, Tamanmartani, Kecamatan Kalasan, Kabupaten Sleman, Yogyakarta Tahun 1985-2013" menjelaskan dengan detail latar belakang kemunculan kesenian srandul di Dusun Karangmojo hingga tahun 2013. Hasil penelitiannya menyatakan bahwa tidak ada keterangan pasti pencipta srandul, beberapa masyarakat beranggapan srandul merupakan sumpah Sunan Kalijaga pada pengikutnya. Srandul termasuk dalam seni teater rakyat, seni tradisi, dan harus dilestarikan karena termasuk kearifan lokal [1].
Supriyanto dalam artikelnya berjudul "Kesenian Srandul dalam Upacara Bersih Desa Bulu Kelurahan Karangmojo Kecamatan Karangmojo Kabupaten Gunungkidul Yogyakarta" memaparkan bahwa srandul di Karangmojo Gunung Kidul lebih sering dipentaskan ketika bersih desa, meskipun juga sebagai tontonan sekuler. Masyarakat desa masih percaya bahwa cikal bakal Dusun Bulu yaitu Kyai Mojo masih menjaga dusun tersebut [4].

Fandy Aprianto Rohman dalam artikelnya berjudul "Jejak Kesenian Srandul di Magelang" khusus membahas kesenian srandul yang ada di Magelang sejak kelahirannya hingga saat ini. Pembahasan srandul dalam artikel yang ditulis oleh Rohman lebih bersifat historis atau kesejarahannya. Hasil dari penelitiannya menyatakan bahwa srandul di Dusun Dukuhan muncul sekitar tahun 1982 dan pementasan sering dilakukan sesuai permintaan masyarakat untuk mengisi acara hajatan [8].

Tujuan dari penelitian ini adalah untuk mengetahui revitalisasi yang terjadi di dalam kesenian srandul khususnya komunitas Srandul Suketeki dan perubahan fungsi yang dialami oleh sastra lisan srandul.

\section{METODE}

Penelitian ini menggunakan metode penelitian etnografi dengan teknik langsung dan wawancara dengan informan. Spradley menyatakan bahwa wawancara dalam metode etnografi bersifat peristiwa percakapan agar informan lebih terbuka sehingga mendapatkan data nyata dan sebanyak banyaknya [9]. Dua metode yang digunakan adalah metode pengumpulan data dan metode analisis data. Metode pengumpulan data digunakan untuk mengumpulkan data berupa objek material berupa kesenian tradisi srandul, sedangkan objek formal adalah teori sastra lisan Ruth Finnegan. Metode pengumpulan data dilakukan dalam dua cara, pertama dengan kepustakaan dan yang kedua dengan pengumpulan data lapangan menggunakan metode etnografi.

Metode pengumpulan data digunakan untuk mengambil data secara langsung di lapangan, mengadakan observasi, wawancara dengan informan dan narasumber, serta menyaksikan langsung pementasan agar nampak perubahan apa yang terjadi di komunitas Srandul Suketeki. Metode studi pustaka digunakan untuk mengolah data yang didapatkan dari lapangan dan mendukung analisis 
data yang dilakukan. Penelitian ini juga menggunakan objek formal berupa teori Ruth Finnegan terkait dengan tiga aspek yang menjadi ciri khusus dari sastra lisan sekaligus fungsi dari sastra lisan srandul.

\section{HASIL DAN PEMBAHASAN}

Kesenian tradisi srandul diawali dengan nyanyian sebagai pembuka pertunjukkan, dikombinasi dengan gerakan atau tarian sederhana oleh lakon. Aspek inilah yang disebut kombinasi joged, tembang, dan tembung. Tetembungan yang dituturkan umumnya berbahasa Jawa, meskipun ada kalanya terkena interferensi bahasa yang lain. Tetembungan tersebut berupa pesan-pesan yang mengajak pada kebaikan, beberapa di antaranya adalah ajakan untuk beribadah, seperti salat dan puasa. Lakon akan memasuki panggung satu persatu dan mulai menjalankan perannya sesuai dengan pakem yang dipegang turun temurun.

Teks dalam sastra lisan merupakan elemen yang paling penting, meskipun berbeda dengan sastra tulis karena sastra lisan memiliki teks verbal, satu potong teks tidak akan memiliki makna jika tidak diaktualisasikan [10]. Pernyataan di atas menjelaskan bahwa teks memang elemen yang paling penting dari sastra lisan, tetapi teks tersebut tidak akan memiliki makna sebelum diadakan pertunjukkan. Hal ini berlaku pula untuk sastra tulis yang tidak bermakna jika belum dimaknai oleh pembaca. Oleh karena itu, melalui apresiasi penonton maupun pembaca, sastra dapat dimaknai bahkan dirasakan fungsinya.

Hutomo menegaskan kembali perbedaan antara sastra tulisan dengan sastra lisan, jika puisi (sastra) tulis setelah dicipta dapat disimpan dan disebarkan bahkan dibacakan berulangkali, sedangkan puisi lisan diciptakan serentak saat pertunjukkan [5]. Hal tersebut memberikan simpulan bahwa pada setiap pertunjukkan sastra lisan, baik dilakonkan oleh orang yang sama dengan cerita yang sama, atau penampil yang berbeda dengan cerita yang sama, dengan kondisi yang berbeda-beda, dan dengan penonton yang berbeda akan memunculkan pemaknaan dan memberikan fungsi yang berbeda. Kondisi di atas dapat terjadi karena dalam sastra lisan para penyanyi (lakon) memiliki semacam patokan cerita dikenal dengan istilah formula [11]. Formula dimaknai sebagai sekumpulan kata yang secara teratur digunakan dalam kondisi metrik yang sama untuk mengekspresikan ide penting yang diberikan.

Membahas sastra lisan, bukan hanya membincang mengenai warisan budaya nenek moyang yang dikenal nir aksara. Sastra lisan adalah sebuah kekayaan budaya yang mengandung berbagai kekayaan dari suatu masyarakat yang bernilai. Selain itu, srandul dapat dikatakan sebagai salah satu kearifan lokal. Kearifan lokal sarat dengan nilainilai agama, karena dari segi asal-usulnya, budaya kearifan lokal merupakan proses cipta rasa manusia yang berpusat dari hati nurani yang jujur, ikhlas, amanah dan cerdas yang memancar di akal pikiran manusia, dan dilaksanakan dengan tindakan dan perbuatan. Munculnya perubahan pada beberapa bagian di kesenian srandul diasumsikan merupakan perubahan yang terjadi karena mengikuti perkembangan teknologi. Perkembangan teknologi dan industri tersebut mau tidak mau memberikan dampak pada perkembangan atau perubahan pola pikir dan cara pandang terhadap segala hal, termasuk kesenian.

[10] menyebutkan bahwa bermunculannya bentuk sastra lisan yang beraneka ragam, bahkan ada beberapa variasi yang dikatakan menyimpang dari bentuk normalnya merupakan hal yang lazim terjadi di masyarakat. Bahkan perubahan-perubahan tersebut dapat menciptakan bentuk baru yang jauh berbeda. Akan tetapi, perubahan yang dilakukan bukan serta merta merupakan sebuah kesengajaan sebagai penggubahan sastra lisan, tetapi sebuah upaya pelestarian dan pemertahanan masyakarat untuk terhadap eksistensi sastra lisan tersebut.

Di era modern yang menuntut keterlibatan teknologi dalam setiap lini kehidupan, bukan menjadi suatu yang aneh jika tradisi turut serta mengikuti arusnya. Tradisi lisan termasuk sastra lisan yang berubah dan beralih menjadi aksara. Hal tersebut dilakukan demi keberlangsungan dan kelestarian sastra lisan, banyak dari tradisi termasuk sastra lisan yang dikaji, dianalisis, dituliskan dalam berbagai media cetak dan karya tulis lainnya.

Sastra lisan dalam perjalanannya pasti akan menjumpai banyak tantangan untuk tetap bertahan, seperti pendapat Suwardi yang menyatakan salah satu penyebab terjadinya perubahan di dalam sastra lisan [12]. Dari berbagai jenis dan ragam sastra lisan, akan bermunculan fenomena di dalamnya. Sastra lisan bisa saja memudar, berbaur, hampir punah, bahkan punah dan menghilang. Sastra lisan yang akan terus bertahan menurut Amir harus memiliki 
ruang untuk improvisasi, adanya keterbukaan untuk menyesuaikan diri dengan kemajuan yang terjadi di masyarakat [13]. Bukan hanya dari segi inti berupa dialog maupun isi cerita, lebih luas dari itu, keterbukaan dalam sastra lisan dapat dilakukan dengan penyesuaian pada aspek lain seperti kostum, instrumen musik, lirik lagu yang menjadi pengiring.

[14] menyatakan dalam jurnal sastra lisan yang ditulisnya bahwa sebuah tradisi harus terus dijalankan atau dilaksanakan oleh masyarakatnya untuk menjaga kelestariannya. Finnegan merupakan salah satu tokoh yang menggeluti bidang sastra lisan. Ia memang tidak menyebutkan secara langsung istilah revitalisasi, dari pernyataan yang diberikan, terlihat bahwa konsep revitalisasi dalam sastra lisan didukung olehnya. Penyesuaian, perubahan, atau modifikasi, bahkan perombakan secara besarbesaran dapat dilakukan dengan menyesuaikan kondisi yang ada di masyarakat. Namun, perlu diperhatikan bahwa modifikasi yang dilakukan tetap memperhatikan inti atau ciri dari sastra lisan tersebut. Perubahan yang dilakukan tidak mengubah inti, ciri khas, dan nilai yang turun temurun terkandung di dalam sastra lisan yang merupakan ciri masyarakat kolektif tersebut.

\section{Revitalisasi di dalam Srandul}

Kesenian srandul, memiliki beberapa aspek yang melekat, tidak hanya berupa teks (sastra lisan) saja, tetapi beberapa aspek pendukung lainnya yang menjadi satu kesatuan sehingga disebut sebagai srandul. Oleh karena itu, proses penghidupan kembali (revitalisasi) tidak hanya diterapkan pada dialog (sastra lisan)-nya saja. Aspek-aspek pendukung yang ada dalam srandul pun turut serta menjadi sasaran modifikasi agar lebih sesuai dengan perkembangan jaman. Ada tiga ciri sebuah puisi (karya sastra) disebut sebagai sastra lisan (1) komposisi, (2) cara pewarisannya, dan (3) pertunjukan [10].

1. Komposisi atau penciptaan sastra lisan adalah dengan lisan. Meskipun pada perkembangannya banyak sastra lisan yang penciptaannya dibantu dengan tulisan.

Hal ini senada dengan srandul Komunitas Suketeki. Pak Kusumo selaku ketua komunitas mengakui bahwa naskah yang akan dipentaskan sebelumnya disusun terlebih dahulu. Hal ini dikarenakan pertunjukkan sastra lisan Srandul Suketeki mengusung kritik sosial politik dan dipentaskan secara umum, sehingga memang perlu pengumpulan data, fakta, dan kehati-hatian.
Meskipun tidak dipungkiri saat di atas panggung terjadi improvisasi oleh para lakon.

Ong [13] menyatakan bahwa hal ini termasuk dalam kelisanan sekunder, yaitu kelisanan yang dibantu dengan tulisan. Meski yang seharusnya dilisankan tetapi dibuat dalam bentuk tulis, tetapi tidak menghapuskan yang lisan. Keduanya tetap hidup bersama dan saling mendukung. Komunitas ini juga memanfaatkan sosial media sebagai pendukung promosi seperti facebook dan youtube.

2. Pewarisan. Salah satu hal mendasar yang menjadi pembeda antara sastra tulis dan sastra lisan terletak pada pewarisannya, sastra lisan diwariskan secara lisan.

Kriteria ini merupakan kriteria yang menjadi penekanan oleh foklor terhadap syarat disebutnya sastra lisan dan menjadi perbedaan yang mencolok dengan sastra tulis. Dalam komunitas Suketeki, pewarisan dilakukan secara tulis dan lisan. ketika akan mengadakan pertunjukkan, para pelakon diberikan gambaran cerita secara umum dengan bantuan naskah.

3. Pertunjukkan. Sastra lisan memiliki formula dan tema yang dipegang oleh para lakon dalam pertunjukkannya. Lakon diberikan kebebasan penuh untuk melakukan improvisasi terhadap cerita dengan catatan tidak menggubah inti cerita atau cerita yang penting.

\section{Perubahan Fungsi dalam Srandul}

Seperti yang telah disampaikan oleh informan bahwa srandul merupakan kesenian yang telah ada sejak masa walisongo. Lamanya waktu penyebaran dan pemertahanan di masyarakat tentu telah mengalami berbagai pasang surut serta perubahan fungsi yang dirasakan di masyarakat sekitar. [15] menyatakan bahwa seringkali sastra lisan menghadirkan makna yang luas (lebih bersifat ambigu) dan itu memang disengaja. Kadang tersirat tetapi seringkali menjadi sumber kesalahpahaman antar pemain maupun pendengar. [5] menyebutkan secara umum sastra lisan di masyarakat memiliki fungsi sebagai system proyeksi, pengesahan kebudayaan, alat pemaksa berlakunya norma-norma sosial dan sebagai alat pengendali sosial, dan alat pendidikan anak. Selain itu, [13] turut berpendapat bahwa fungsi utama dan pertama sastra lisan adalah untuk hiburan, fungsi kedua adalah menyimpan puitika kosakata yang kaya, fungsi ketiga sebagai sarana Pendidikan, untuk sosialisasi nilai-nilai, 
fungsi keempat sebagai ajang nostalgia, fungsi kelima sarana mengumpulkan orang untuk menghimpun dana, dan saat ini muncul fungsi keenam yaitu mengumpulkan orang untuk mendengarkan pesan politik, perkenalan politik, dan sosialisasi program. Lebih dari itu, sastra lisan juga memiliki fungsi secara luas untuk menentang otoritas politik, sindiran, propaganda, pamer, tradisi ritual, pengungkapan cinta, keluhan, luapan emosi tersembunyi yang tidak bisa dikatakan, menipu, mediasi jiwa manusia, menghibur wisatawan asing, mencari nafkah, parodi, memunculkan skandal, menghibur, dan lainnya.

Lebih lanjut lagi, [10] mengatakan bahwa penentuan fungsi sastra lisan harus memperhatikan budaya setempat. Beberapa di antaranya adalah pandangan lokal (masyarakat) misalnya kepercayaan, religi, pengalaman, maupun lambang dan symbol khusus yang digunakan. Saat ini, sastra lisan mampu difungsikan sebagai media protes, menyampaikan aspirasi kepada pemimpin dengan cara yang halus. Sama halnya di masa yang lalu, kesenian selalu berhasil menjadi wahana penyampai aspirasi maupun permintaan rakyat kepada pimpinannya. Dalam hal ini, sastra lisan berfungsi sebagai media aspirasi rakyat. Melalui sastra lisan, protes terhadap kebijakan pemerintah yang bersifat sosial politik atau dalam hal apapun dapat tersampaikan dan terkemas dengan apik. Selain itu, fungsi dari sastra lisan ini juga lebih bersifat sebagai protes halus dan mudah mengena.

Pemaparan kondisi di atas merupakan kondisi yang melatarbelakangi kebutuhan untuk mengadakan revitalisasi bagi srandul. Hal tersebut secara langsung berimbas pada terjadinya beberapa perubahan, termasuk aspek-aspek pertunjukkan yang melekat beserta fungsi yang menjadi dampak bagi masyarakat sekitarnya. Oleh karena itu, selain teks yang terdapat dalam sastra lisan srandul Komunitas Suketeki, perlu dideskripsikan dan dianalisis aspek-aspek yang turut menjadi pendukung sastra lisan saat dipertunjukkan yang mengalami revitalisasi. Aspek-aspek tersebut meliputi: instrumen pengiring, musik, kostum (busana), tata rias, gerak tari, dan tata panggung.
Tabel 1. Aspek dalam srandul yang mengalami revitalisasi

\begin{tabular}{ccc}
\hline Aspek & Sebelum & Srandul \\
yang & Revitalisasi & Suketeki \\
Mengalami & & \\
Revitalisasi & & \\
\hline
\end{tabular}

\begin{tabular}{ll}
\hline $\begin{array}{l}\text { Sastra lisan } \\
\text { (narasi dan }\end{array}$ & Sesuai pakem \\
dialog) & yang turun \\
& temurun \\
& diwariskan \\
& melalui lisan. \\
& Bercerita \\
& mengenai alur \\
& kehidupan Ki \\
& Demang \\
& Cokroyudha \\
& dan \\
& permasalahan \\
& kademangannya \\
& serta \\
& Dhadhungawuk \\
& sebagai \\
& penyelamat.
\end{tabular}

Lebih menonjolkan pada kritik terhadap masalah yang ada pada masyarakat saat ini. Sebenarnya permasalahan korupsi telah disinggung dalam kesenian srandul sebelum adanya revitalisasi tetapi hanya sebagian kecil saja. Di sini porsi tersebut diperbanyak, bahkan menjadi gagasan utama dalam pertunjukan.

\begin{tabular}{|c|c|c|}
\hline $\begin{array}{l}\text { Intrumen } \\
\text { Pengiring }\end{array}$ & $\begin{array}{l}\text { Kendang, } \\
\text { terbang, } \\
\text { angklung, } \\
\text { kadang-kadang } \\
\text { ditambah } \\
\text { dengan kecapi. }\end{array}$ & $\begin{array}{l}\text { Kendang, } \\
\text { terbang, } \\
\text { angklung. }\end{array}$ \\
\hline $\begin{array}{l}\text { Lirik lagu } \\
\text { dan } \\
\text { nyanyian }\end{array}$ & $\begin{array}{l}\text { Lagu-lagu yang } \\
\text { digunakan } \\
\text { untuk } \\
\text { mengiringi } \\
\text { masuk dan } \\
\text { keluarnya tokoh } \\
\text { sekaligus } \\
\text { backsong } \\
\text { berupa parikan, } \\
\text { wangsalan, } \\
\text { lagu dolanan } \\
\text { dan lagu-lagu } \\
\text { daerah. }\end{array}$ & $\begin{array}{l}\text { Masih meniru } \\
\text { Srandul } \\
\text { sebelumnya, } \\
\text { menggunakan } \\
\text { parikan, } \\
\text { wangsalan } \\
\text { tetapi } \\
\text { menyesuaikan } \\
\text { cerita yang } \\
\text { dibuat. Lagu- } \\
\text { lagu dolanan } \\
\text { pun turut } \\
\text { dilagukan saat } \\
\text { mengiringi }\end{array}$ \\
\hline
\end{tabular}




\begin{tabular}{|c|c|c|}
\hline $\begin{array}{c}\text { Aspek } \\
\text { yang } \\
\text { Mengalami } \\
\text { Revitalisasi }\end{array}$ & $\begin{array}{c}\text { Sebelum } \\
\text { Revitalisasi }\end{array}$ & $\begin{array}{l}\text { Srandul } \\
\text { Suketeki }\end{array}$ \\
\hline Kostum & $\begin{array}{l}\text { Sesuai dengan } \\
\text { kedudukan dan } \\
\text { karakter } \\
\text { masyarakat } \\
\text { Jawa di masa } \\
\text { dulu. }\end{array}$ & $\begin{array}{l}\text { tokoh masuk } \\
\text { maupun keluar. } \\
\text { Ki Demang } \\
\text { yang biasanya } \\
\text { mengenakan } \\
\text { blangkon, } \\
\text { sekarang } \\
\text { mengenakan } \\
\text { topi demang } \\
\text { yang identik } \\
\text { dengan } \\
\text { kompeni. }\end{array}$ \\
\hline Tata Rias & $\begin{array}{l}\text { Tegas, kuat, } \\
\text { mencerminkan } \\
\text { karakter dari } \\
\text { masing-masing } \\
\text { tokoh. }\end{array}$ & $\begin{array}{l}\text { Riasan tipis } \\
\text { tetapi masih } \\
\text { menonjolkan } \\
\text { karakter dari } \\
\text { masing-masing } \\
\text { tokoh. }\end{array}$ \\
\hline Gerak Tari & $\begin{array}{l}\text { Setiap tokoh } \\
\text { memiliki } \\
\text { gerakan } \\
\text { masing-masing } \\
\text { saat masuk } \\
\text { maupun keluar } \\
\text { dari arena } \\
\text { panggung. }\end{array}$ & $\begin{array}{l}\text { Tetap } \\
\text { mencerminkan } \\
\text { karakter dari } \\
\text { masing-masing } \\
\text { tokoh. Ki } \\
\text { Demang yang } \\
\text { kalem, } \\
\text { Dhadhungawuk } \\
\text { yang gagah, } \\
\text { maupun } \\
\text { Maling Soka } \\
\text { yang banyak } \\
\text { tingkah. }\end{array}$ \\
\hline $\begin{array}{l}\text { Tata } \\
\text { Panggung }\end{array}$ & $\begin{array}{l}\text { Sudah dapat } \\
\text { bersifat } \\
\text { fleksibel, tidak } \\
\text { harus berada di } \\
\text { ruang terbuka } \\
\text { atau lapangan. } \\
\text { Di dalam } \\
\text { ruangan dan } \\
\text { siang hari, } \\
\text { kesenian } \\
\text { Srandul pun } \\
\text { dapat } \\
\text { dipentaskan. }\end{array}$ & $\begin{array}{l}\text { Mengincar } \\
\text { tempat-tempat } \\
\text { yang eksklusif } \\
\text { dan sering } \\
\text { didatangi oleh } \\
\text { orang-orang } \\
\text { besar dengan } \\
\text { tujuan aspirasi } \\
\text { yang ingin } \\
\text { disampaikan } \\
\text { dapat } \\
\text { tersampaikan } \\
\text { dengan } \\
\text { maksimal. } \\
\text { Beberapa di } \\
\text { antaranya } \\
\text { adalah di } \\
\text { Taman Budaya }\end{array}$ \\
\hline
\end{tabular}

\begin{tabular}{ccc}
\hline $\begin{array}{c}\text { Aspek } \\
\text { yang } \\
\text { Mengalami } \\
\text { Revitalisasi }\end{array}$ & $\begin{array}{c}\text { Sebelum } \\
\text { Revitalisasi }\end{array}$ & $\begin{array}{c}\text { Srandul } \\
\text { Suketeki }\end{array}$ \\
\hline & & \\
\hline & & $\begin{array}{l}\text { Yogyakarta } \\
\text { dan Tembi. }\end{array}$ \\
\hline
\end{tabular}

Dari penjabaran kolom di atas menunjukkan bahwa hanya beberapa aspek dari srandul Komunitas Suketeki yang mengalami perubahan dalam rangka penyesuaian diri dengan situasi dan kondisi yang telah dijabarkan sebelumnya. Revitalisasi yang terlihat mencolok pada srandul Komunitas Suketeki terletak pada teksnya yang menonjolkan kritik pada fenomena yang tengah terjadi di masyarakat. Meskipun demikian, srandul yang dipentaskan tetap mengandung nilai-nilai kehidupan yang menjadi sebuah ciri dari kesenian tradisional. Melalui revitalisasi, para pegiat berharap bahwa srandul tetap eksis dan bertahan di tengah hiruk pikuk kepunahan kesenian tradisional, khususnya sastra lisan. Seperti halnya pesan Pak Kusumo yang menyatakan bahwa melestarikan bukan berarti mempertahankan bentuk tetapi membuat kesenian mampu bertahan dengan langkah nyata berupa pengembangan. Hal ini terbukti dengan srandul garapan Pak Kusumo dan kawan-kawan di Dukuh Karangmojo, Kalasan mampu bangkit dan membawa srandul ke panggung yang lebih luas daripada sekadar lapangan desa.

Dalam upaya revitalisasi yang dilakukan, ciri khas dari kesenian srandul tetap dipertahankan, seperti alat musik yang digunakan, tokoh-tokoh yang bermain di dalamnya, aturan masuk dan keluarnya pemain. Secara umum, hanya teks cerita yang ditambah dan sedikit digubah dengan tujuan menyampaikan kritik sosial. Hal inilah yang menjadikan srandul yang dipentaskan Komunitas Suketeki menjadi sebuah tontonan dengan cerita yang berani, segar, sehingga mendapatkan berbagai dukungan sehingga pihak yang dapat dikatakan sebagai tempat tontonan bergengsi seperti Rumah Budaya Tembi, Bantul dan Taman Budaya Yogyakarta besedia untuk mementaskan kesenian ini. Hal ini tentu saja membuat fungsi yang terkandung dalam srandul pun mengalami perubahan seperti yang dijabarkan dalam Tabel 2. 
Tabel 2. Perbandingan fungsi srandul sebelum dan sesudah mengalami revitalisasi

Srandul sebelum
revitalisasi

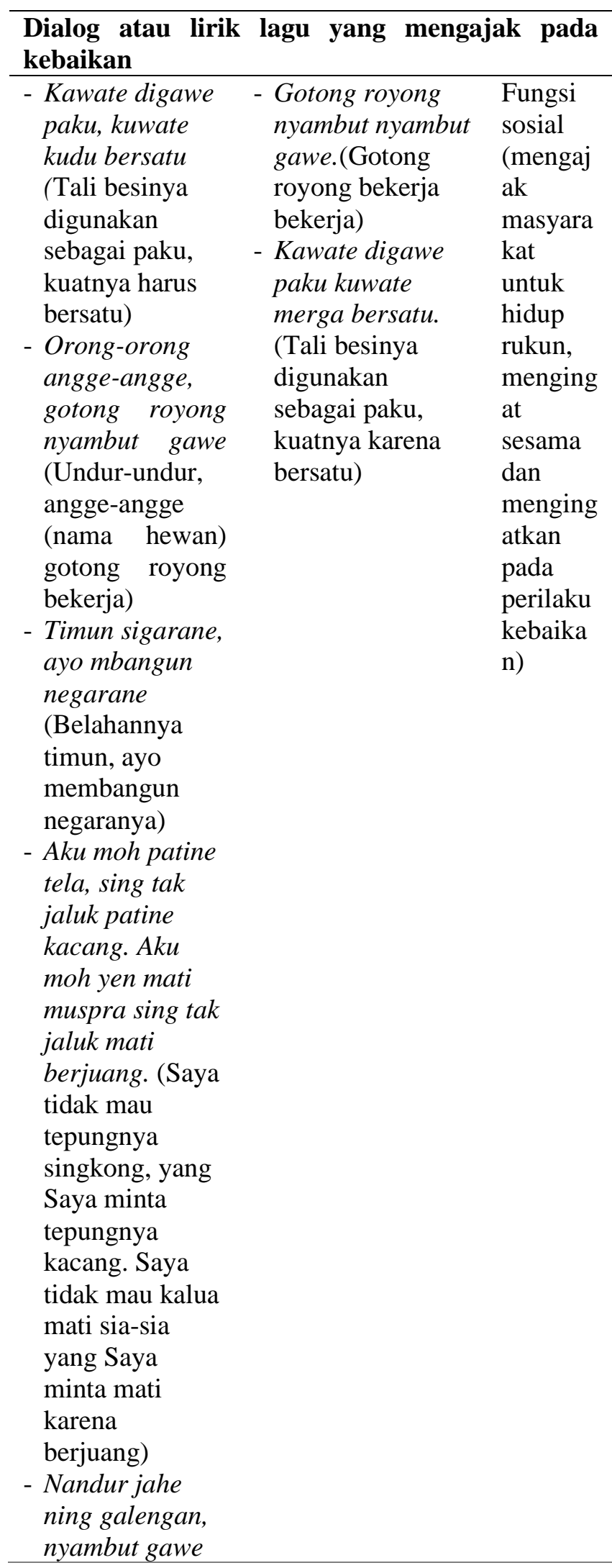

\begin{tabular}{|c|c|c|}
\hline $\begin{array}{l}\text { Srandul sebelum } \\
\text { revitalisasi }\end{array}$ & Srandul Suketeki & Fungsi \\
\hline \multicolumn{3}{|l|}{$\begin{array}{l}\text { bebarengan } \\
\text { (Menanam jahe } \\
\text { di tegalan, } \\
\text { bekerja } \\
\text { bersama-sama) }\end{array}$} \\
\hline \multicolumn{3}{|c|}{ Dialog atau lirik tentang agama } \\
\hline $\begin{array}{l}\text { - Ma lima ki } \\
\text { larangane } \\
\text { agama, kowe } \\
\text { wani-wania } \\
\text { ngono (dialog). } \\
\text { (Ma lima itu } \\
\text { larangannya } \\
\text { agama, Kamu } \\
\text { jangan berani- } \\
\text { berani seperti } \\
\text { itu) } \\
\end{array}$ & & $\begin{array}{l}\text { Fungsi } \\
\text { Religi } \\
\text { (mengin } \\
\text { gatkan } \\
\text { tentang } \\
\text { aturan } \\
\text { agama) }\end{array}$ \\
\hline \multicolumn{3}{|c|}{ Dialog atau lirik berisi nasihat } \\
\hline 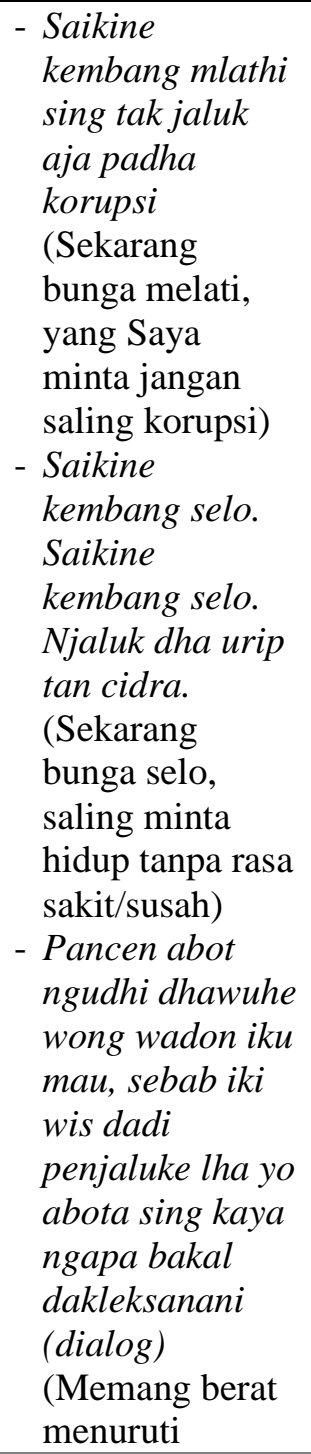 & $\begin{array}{l}\text { - Kembang } \\
\text { landhep } \\
\text { kembange } \\
\text { munggur (yo). } \\
\text { Yen pengen } \\
\text { slamet yo kudu } \\
\text { jujur (Bunga } \\
\text { yang tajam bunga } \\
\text { munggur (yo). } \\
\text { Jika ingin selamat } \\
\text { ya harus jujur) } \\
\text { - Kuwi apa kuwi e } \\
\text { kembang melati. } \\
\text { Sing tak pujo } \\
\text { puji. Aja dha } \\
\text { korupsi merga } \\
\text { yen korupsi } \\
\text { negarane rugi } \\
\text { (Itu apa itu e } \\
\text { bunga melati. } \\
\text { Yang ku puja } \\
\text { puji. Jangan } \\
\text { saling korupsi } \\
\text { karena jika } \\
\text { korupsi, } \\
\text { negaranya rugi) } \\
\text { - Ning kene iki } \\
\text { rasaning ati. Rasa } \\
\text { risi pejabate dha } \\
\text { korupsi. Rakyate } \\
\text { kabeh padha } \\
\text { diapusi. Akhire } \\
\text { negarane saya }\end{array}$ & $\begin{array}{l}\text { Fungsi } \\
\text { pendidik } \\
\text { an/mora } \\
1 \\
\text { (media } \\
\text { masyara } \\
\text { kat } \\
\text { untuk } \\
\text { mendidi } \\
\text { k dan } \\
\text { menyisi } \\
\text { pkan } \\
\text { pendidik } \\
\text { an } \\
\text { karakter } \\
\text { kepada } \\
\text { generasi } \\
\text { penerus) }\end{array}$ \\
\hline
\end{tabular}




\begin{tabular}{|c|c|c|c|c|c|}
\hline $\begin{array}{c}\text { Srandul sebelum } \\
\text { revitalisasi }\end{array}$ & Srandul Suketeki & Fungsi & $\begin{array}{c}\text { Srandul sebelum } \\
\text { revitalisasi }\end{array}$ & Srandul Suketeki & Fungsi \\
\hline \multirow{3}{*}{$\begin{array}{l}\text { permintaan } \\
\text { perempuan itu, } \\
\text { karena ini sudah } \\
\text { menjadi } \\
\text { permintaannya, } \\
\text { beratnya seperti } \\
\text { apa tetap akan } \\
\text { Saya } \\
\text { laksanakan) }\end{array}$} & \multirow{3}{*}{$\begin{array}{l}\text { rugi. Mbok eling } \\
\text { kanca kabeh } \\
\text { enggala lek } \\
\text { diadhili (Di } \\
\text { sinilah rasanya } \\
\text { hati/perasaan. } \\
\text { Perasaan rishi } \\
\text { para pejabatnya } \\
\text { korupsi. Semua } \\
\text { rakyatnya ditipu. } \\
\text { Akhirnya } \\
\text { negaranya } \\
\text { bertambah rugi. } \\
\text { Ayo sadarlah, } \\
\text { ingat teman semua } \\
\text { segera diadili) }\end{array}$} & & & & $\begin{array}{l}\text { diikuti } \\
\text { oleh } \\
\text { semua } \\
\text { masyara } \\
\text { kat) }\end{array}$ \\
\hline & & & \multicolumn{2}{|c|}{ Kebiasaan jaman dahulu } & \\
\hline & & & $\begin{array}{l}\text { - Ana prenjak } \\
\text { ngganter- } \\
\text { ngganter }\end{array}$ & $\begin{array}{l}\text { - Biasane nek } \\
\text { wonten manuk } \\
\text { nggantar- } \\
\text { nggantar ngoten } \\
\text { ajeng wonten } \\
\text { dhayoh (dialog) }\end{array}$ & $\begin{array}{l}\text { Fungsi } \\
\text { dokume } \\
\text { ntasi/sej } \\
\text { arah } \\
\text { (mereka } \\
\mathrm{m} \\
\text { kebiasaa } \\
\mathrm{n} \\
\text { masyara }\end{array}$ \\
\hline \multicolumn{3}{|l|}{ Paribasan } & & & \\
\hline \multirow{3}{*}{$\begin{array}{l}\text { - Anak polah } \\
\text { bapa kepradah } \\
\text { (dialog) } \\
\text { - Rawe-rawe } \\
\text { rantas malang- } \\
\text { malang putung } \\
\text { (dialog) } \\
\text { - Sura dira } \\
\text { jayaningrat } \\
\text { lebur dening } \\
\text { pangastuti } \\
\text { - Munggah } \\
\text { gunung mudhun } \\
\text { gunung }\end{array}$} & \multirow[b]{3}{*}{$\begin{array}{l}\text { - Apa meneh ana } \\
\text { unen-unen. Jane } \\
\text { ajining dhiri } \\
\text { priya kuwi saka } \\
\text { bandha, praja, } \\
\text { pangkat, lan } \\
\text { wanita (Apa lagi } \\
\text { ada peribahasa. } \\
\text { Katanya } \\
\text { berharganya diri } \\
\text { lelaki itu dari } \\
\text { harta, jabatan, } \\
\text { pangkat, dan } \\
\text { wanita) } \\
\text { - Kang becik } \\
\text { ketitik, kang ala } \\
\text { ketara. Kang } \\
\text { temen tinemu } \\
\text { kang salah bakal } \\
\text { seleh. sura dira } \\
\text { jayaningrat lebur } \\
\text { dening } \\
\text { pangastuti. }\end{array}$} & \multirow[b]{3}{*}{$\begin{array}{l}\text { Fungsi } \\
\text { pendidik } \\
\text { an/mora } \\
1 \\
\text { (membe } \\
\text { rikan } \\
\text { nasihat } \\
\text { tetapi } \\
\text { tidak } \\
\text { secara } \\
\text { tersurat. } \\
\text { Selain } \\
\text { itu, } \\
\text { paribas } \\
\text { an } \\
\text { dalam } \\
\text { Srandul } \\
\text { tersebut } \\
\text { dapat } \\
\text { dikataka } \\
\text { n } \\
\text { sebagai } \\
\text { represen } \\
\text { tasi atas } \\
\text { norma } \\
\text { atau } \\
\text { nilai } \\
\text { sosial } \\
\text { dari } \\
\text { sebuah } \\
\text { masyara } \\
\text { kat, } \\
\text { diterima } \\
\text { dan }\end{array}$} & & & $\begin{array}{l}\text { jaman } \\
\text { dahulu) }\end{array}$ \\
\hline & & & Sindiran & & \\
\hline & & & - & $\begin{array}{l}\text { - Sayuk rukun karo } \\
\text { kancane nyilih } \\
\text { kloso kanggo } \\
\text { resepsi (yo mas } \\
\text { yo) sugih bandha } \\
\text { merga korupsi } \\
\text { (Rukun dengan } \\
\text { temannya, } \\
\text { meminjam tikar } \\
\text { untuk resepsi } \\
\text { (ayo mas ayo) } \\
\text { kaya harta karena } \\
\text { korupsi) } \\
\text { - Tuku kupat } \\
\text { kanggo sarapan } \\
\text { (yo mas yo) } \\
\text { njaluk surat } \\
\text { ndadak } \\
\text { amplopan. } \\
\text { Jungkate } \\
\text { tumumpang kursi. } \\
\text { Pejabate } \\
\text { manipulasi. (Beli } \\
\text { kupat untuk } \\
\text { sarapan (ayo mas } \\
\text { ayo) minta surat } \\
\text { harus beramplop. } \\
\text { Sisirnya di atas } \\
\text { kursi. Pejabatnya } \\
\text { manipulasi) }\end{array}$ & $\begin{array}{l}\text { Fungsi } \\
\text { sosial } \\
\text { (diguna } \\
\text { kan } \\
\text { untuk } \\
\text { menega } \\
\text { kkan } \\
\text { maupun } \\
\text { menenta } \\
\text { ng } \\
\text { otoritas } \\
\text { politik/k } \\
\text { ebijakan } \\
\text { pemerin } \\
\text { tah) }\end{array}$ \\
\hline
\end{tabular}




\begin{tabular}{|c|c|c|c|c|c|}
\hline $\begin{array}{l}\text { Srandul sebelum } \\
\text { revitalisasi }\end{array}$ & Srandul Suketeki & Fungsi & $\begin{array}{l}\text { Srandul sebelum } \\
\text { revitalisasi }\end{array}$ & Srandul Suketeki & Fungsi \\
\hline & 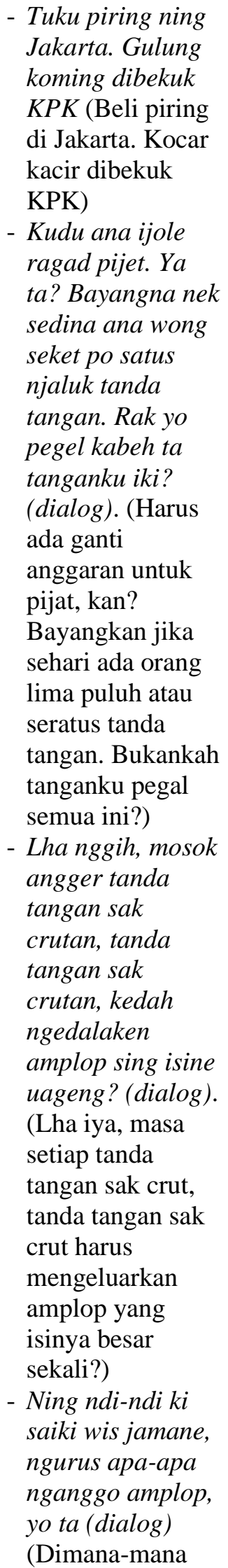 & & & 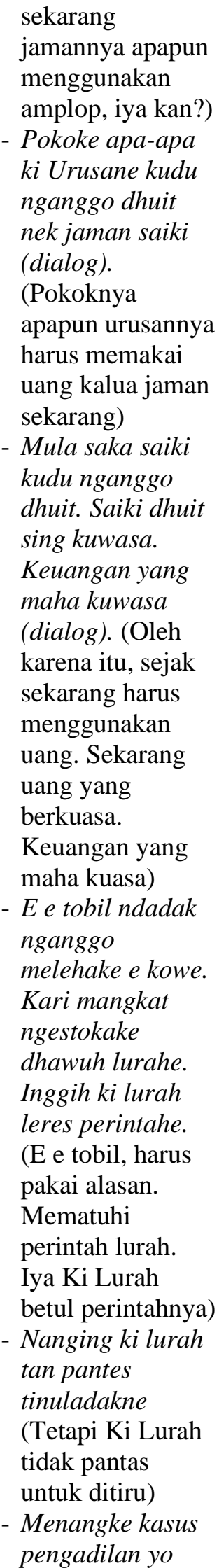 & \\
\hline
\end{tabular}




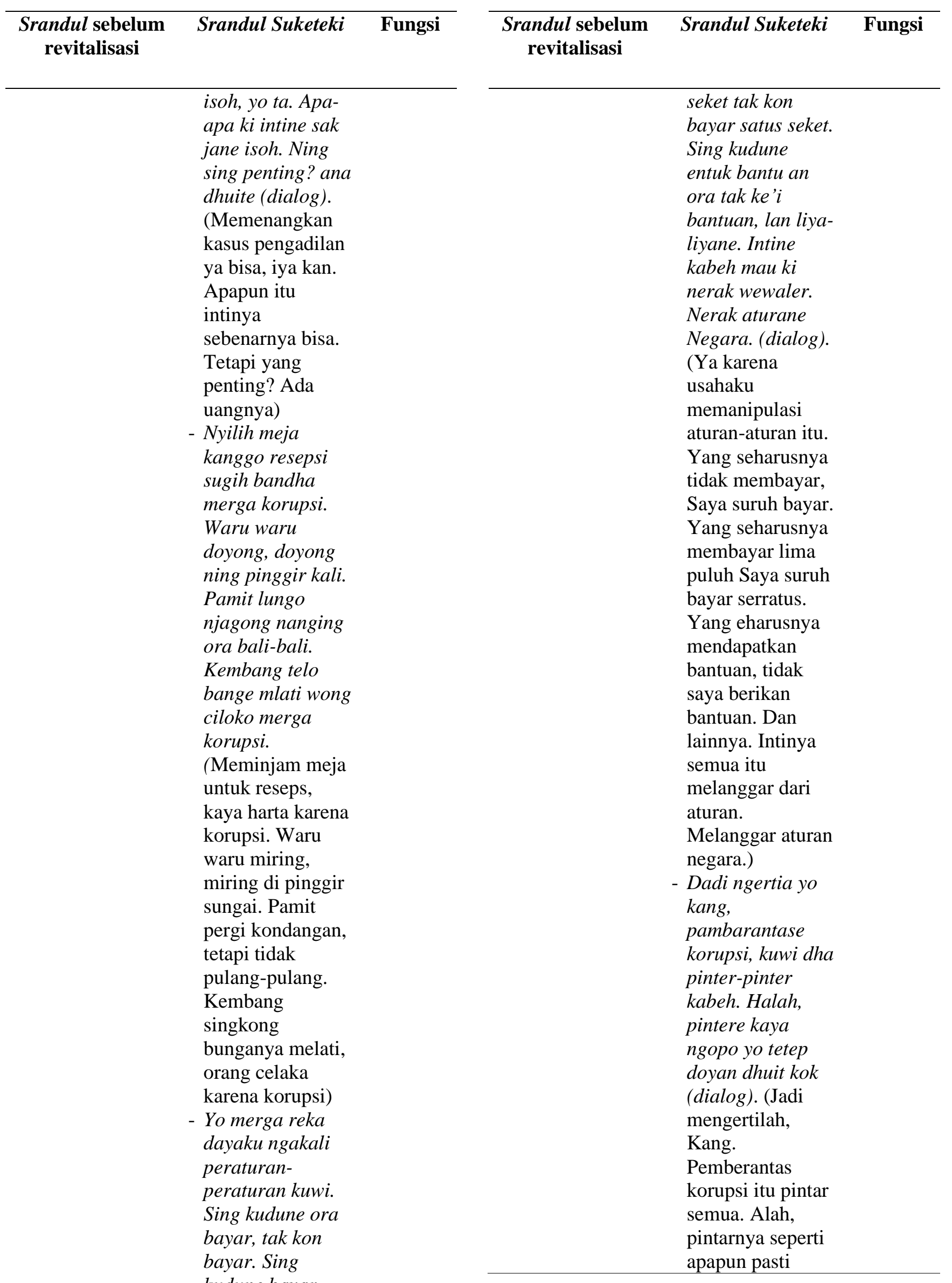




\begin{tabular}{ccc}
\hline $\begin{array}{c}\text { Srandul sebelum } \\
\text { revitalisasi }\end{array}$ & Srandul Suketeki & Fungsi
\end{tabular}

doyan dengan

uang kok)

\begin{tabular}{|c|c|c|c|}
\hline \multicolumn{4}{|l|}{ Aspirasi } \\
\hline & & 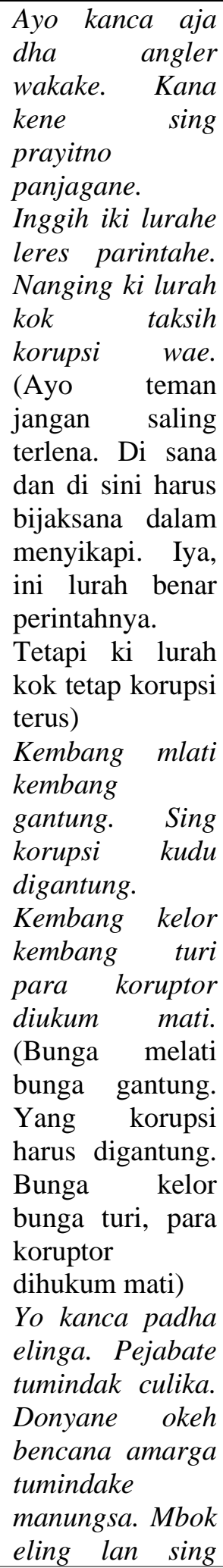 & $\begin{array}{l}\text { Fungsi } \\
\text { sosial } \\
\text { (menya } \\
\text { mpaikan } \\
\text { keingina } \\
\text { n dari } \\
\text { masyara } \\
\text { kat baik } \\
\text { secara } \\
\text { tersurat } \\
\text { maupun } \\
\text { tersirat) }\end{array}$ \\
\hline
\end{tabular}

\begin{tabular}{|c|c|c|}
\hline $\begin{array}{l}\text { Srandul sebelum } \\
\text { revitalisasi }\end{array}$ & Srandul Suketeki & Fungsi \\
\hline & $\begin{array}{l}\text { waspadha. } \\
\text { Negarane dhasar } \\
\text { pancasila. Wis } \\
\text { pasraha Kang } \\
\text { Kuwasa becik } \\
\text { ketitik ala ketara. } \\
\text { (Ayo teman, } \\
\text { ingatlah. } \\
\text { Pejabatnya } \\
\text { bertindak curang. } \\
\text { Dunia banyak } \\
\text { musibah karena } \\
\text { perbuatan } \\
\text { manusia. Ayolah } \\
\text { saling ingat dan } \\
\text { waspada. Negara } \\
\text { berdasarkan } \\
\text { Pancasila. } \\
\text { Pasrahkan pada } \\
\text { Yang Kuasa. } \\
\text { Yang baik akan } \\
\text { Nampak, dan } \\
\text { yang buruk pun } \\
\text { akan terlihat) }\end{array}$ & \\
\hline \multicolumn{3}{|l|}{ Lagu selingan } \\
\hline $\begin{array}{ll} & \text { Lumbung desa } \\
- & \text { Numpak } \\
& \text { andhong } \\
- & \text { Buto-buto } \\
& \text { galak } \\
-\quad & \text { Macapat } \\
\quad \text { (kinanthi) } \\
-\quad \text { Semut ireng } \\
-\quad \text { Witing klapa } \\
\text { - } \quad \text { Mari kangen } \\
\text { (mayoritas adalah } \\
\text { lagu-lagu daerah } \\
\text { jaman dahulu) }\end{array}$ & $\begin{array}{l}\text { - Buto-buto galak } \\
\text { (meminimalisir } \\
\text { lagu-lagu selingan) }\end{array}$ & $\begin{array}{l}\text { Fungsi } \\
\text { hiburan }\end{array}$ \\
\hline
\end{tabular}

Dari penjabaran data di atas, dapat dilihat beberapa fungsi tambahan yang terdapat dalam lirik lagu yang dinyanyikan maupun dialog para lakon. Selain itu, lagu-lagu daerah dan campursari yang dibawakan merupakan hiburan bagi penonton. Beberapa fungsi utama tetap dipertahankan sebagai ciri bahwa srandul hadir dengan berbagai nilai yang dikandungnya. Fungsi tambahan yang terlihat dan menonjol di Srandul Komunitas Suketeki dapat dilihat dalam Tabel 3. 
Tabel 3. Fungsi Srandul Suketeki Fungsi Awal Srandul Srandul Suketeki

\begin{tabular}{lll}
\hline - $\begin{array}{l}\text { Fungsi religi } \\
\text { (sebagai media } \\
\text { penyebar agama } \\
\text { Islam ke } \\
\text { masyarakat) }\end{array}$ & $\bullet \begin{array}{l}\text { Fungsi sosial } \\
\text { (kritik/penyampai } \\
\text { aspirasi) }\end{array}$ \\
$\begin{array}{l}\text { Fungsi sosial (ajakan } \\
\text { hidup rukun antar } \\
\text { sesama masyarakat) }\end{array}$ & \\
\hline
\end{tabular}

Srandul pada mulanya berfungsi sebagai sarana penyebaran agama islam, memperkenalkan islam pada masyarakat dengan pendekatan budaya dan fungsi sosial yang mengajak masyarakat untuk hidup rukun. Dalam proses revitalisasi mengalami fungsi tambahan. Selain mempertahankan kedua fungsi tersebut, bertambah menjadi penyampai aspirasi dan kritik sekaligus berfungsi sebagai hiburan dengan menyisipkan lagu-lagu baru yang mengikuti jaman serta guyonan yang menyentil kondisi saat ini.

\section{KESIMPULAN}

Revitalisasi yang dilakukan oleh Komunitas Srandul Suketeki yang berada di Dusun Karangmojo yang dipandegani oleh Pak Kusumo memberikan angin segar. Tontonan yang dikenal sebagai kesenian tradisi dibawakan dengan suasana baru yang menarik minat penonton. Hal ini merupakan salah satu upaya pelestarian, pemertahanan, bahkan pengembangan sastra lisan di tengah arus perkembangan teknologi yang semakin canggih.

Revitalisasi yang dilakukan tidak hanya dalam teks (sastra lisan) saja tetapi juga aspek-aspek pertunjukan lainnya, meliputi: instrumen pengiring, musik, kostum (busana), tata rias, gerak tari, dan tata panggung. Dari semua aspek revitalisasi tersebut, revitalisasi atau perubahan/pengembangan paling terlihat adalah dalam aspek narasi cerita/dialog yang merupakan sastra lisan. Teks cerita disisipi kritik sosial dan penyampaian aspirasi kepada pemimpin. Terjadinya revitalisasi di dalam srandul ini secara otomatis menyebabkan perubahan fungsi yang turut melekat dalam kesenian maupun sastra lisan srandul. Srandul yang dahulunya lebih difungsikan sebagai media dakwah yang digunakan oleh para wali kini menjadi sarana hiburan bagi warga, bahkan menjadi salah satu media dalam menyampaikan aspirasinya kepada pemerintahan. Melalui revitalisasi terbukti bahwa sastra lisan srandul mampu bertahan dan menarik minat serta keingintahuan masyarakat untuk menonton, bahkan beberapa pihak menyambut baik dan mendukung secara positif.

\section{REFERENSI}

[1] Sulistianto, "Kesenian Srandul di Dusun Karangmojo, Tamanmartani, Kecamatan Kalasan, Kabupaten Sleman Yogyakarta Tahun 1985-2013," e-Journal Pendidikan Sejarah, vol. 4, no. 1, 2016.

[2] Jabrohim, "Pemanfaatan Srandul sebagai Salah Satu Alternatif Pendukung Dakwah Islam melalui Karya Seni," Tsaqafa, Jurnal Kajian Seni Budaya Islam, vol. 1, no. 1, 2012.

[3] L. Anggraini, "Tinjauan Koreografi Kesenian Srandul Ngesti Budhoyo di Desa Gebangharjo, Kecamatan Pracimantoro , Kabupaten Wonogiri," Skripsi Pendidikan Seni Tari, Fakultas Bahasa dan Seni, Universitas Negeri Yogyakarta, Yogyakarta, 2016.

[4] Supriyanto, "Kesenian srandul dalam Upacara Bersih Desa Bulu Kelurahan Karangmojo Kecamatan Karangmojo Kabupaten Gunung Kidul Yogyakarta," Sitakara, vol. V, no. 2, 2020.

[5] S. S. Hutomo, Mutiara yang Terlupakan Pengantar Studi Sastra Lisan, Surabaya: 1991, 1991.

[6] R. A. Widihastuti, "Revitalisasi, Perubahan Fungsi, dan Perubahan Konteks Sosial Masyarakat dalam Sastra Lisan Srandul di Dukuh Plempoh dan Dukuh Karangmojo, Yogyakarta," Tesis Ilmu Sastra Universitas Universitas Gajah Mada, Yogyakarta, 2015.

[7] Sunahrowi, "Pembentukan Karakter Anak melalui Kesenian Tadisional Srandul: Kajian Semiotika Roland Barthes," Insania, vol. 20, no. 1, 2015.

[8] F. A. Rohman, "Jejak Kesenian Srandul di Magelang," Pangandereng: Jurnal Hasil Penelitian Ilmu Sosial dan Humaniora, vol. 6, no. 2, 2020.

[9] J. P. Spradley, Metode Etnografi, Yogyakarta: Tiara Wacana, 2007.

[10] R. Finnegan, Oral Poetry: Its Nature, Significance, and Sosial Context, London : Cambridge University Press, 1979. 
[11] A. B. Lord, The Singer of Tales, New York: Atheneum, 1976.

[12] S. Endraswara, Metodologi Penelitian Sastra: Epistemologi Model, Teori, dan Aplikasi, Yogyakarta: Pustaka Widyatama, 2004.

[13] A. Amir, Sastra Lisan Indonesia, Yogyakarta: CV. Andi Offset, 2013.
[14] R. Finnegan, "Tradition, But What Tradition and For Whom?," Oral Tradition Journal, vol. 6, no. 1, 1991.

[15] R. Finnegan, Oral Traditions and the Verbal Arts, New York : Routledge, 1992. 